\title{
A iniciativa popular em Saúde: a participação da sociedade no Congresso Nacional no período de 2011 a 2015
}

The popular initiative in Health: the participation of society in the National Congress in the period from 2011 to 2015

La iniciativa popular en Salud: la participación de la sociedad en el Congreso Nacional en el período de 2011 a 2015

Ivan Pricken de Bem ${ }^{1}$

RESUMO: Objetivo: analisar e discutir as formas de participação da comunidade na proposição de leis com o tema da saúde na instância legislativa federal representada pela Câmara dos Deputados e Senado Federal. Metodologia: foi feita uma pesquisa exploratória na base de dados das duas casas legislativas nos projetos de lei considerados de iniciativa popular na área da saúde, para conhecer seu conteúdo material e tramitação. Resultados: há um baixo número de proposições legislativas por iniciativa popular no tema da saúde em vista do desconhecimento dos cidadãos e do baixo interesse dos parlamentares sobre essas comissões de participação. Conclusão: apesar de garantido, o instrumento da iniciativa popular em especial na saúde ainda é pouco utilizado no Brasil e não se vislumbra um apoio parlamentar para tais iniciativas.

Palavras-chave: Saúde Pública. Participação da comunidade. Poder Legislativo

ABSTRACT: Objective: to analyze and discuss ways of community participation in proposing health-related laws in the federal legislative body represented by the House of Representatives and the Federal Senate. Methods: an exploratory research was carried out in the database of the two legislative houses in the bills considered popular initiative in the area of health, to know their material content and procedure. Results: there is a small number of legislative proposals on the initiative of the people on health in view of the lack of knowledge of the citizens and the low interest of parliamentarians on these participation committees. Conclusion: Although guaranteed, the instrument of popular initiative in health is still little used in Brazil and there is no sign of parliamentary support for such initiatives.

Keywords: Public Health. Community Participation. Legislative.

RESUMEN: Objetivo: analizar y discutir las formas de participación de la comunidad en la proposición de leyes con el tema de la salud en la instancia legislativa federal representada por la Cámara de Diputados y Senado Federal. Metodología: se realizó una investigación exploratoria en la base de datos de las dos casas legislativas en los proyectos de ley considerados de iniciativa popular en el área de la salud, para conocer su contenido material y tramitación. Resultados: hay un bajo número de proposiciones legislativas por iniciativa popular en el tema de la salud en vista del desconocimiento de los ciudadanos y del bajo interés de los parlamentarios sobre esas comisiones de participación.

\footnotetext{
${ }^{1}$ Bacharel em Saúde Coletiva pela Universidade de Brasília. Especialista em Direito Sanitário e Mestrando em Políticas Públicas em Saúde pela Fundação Oswaldo Cruz Brasília.
} 
Conclusión: a pesar de estar garantizado, el instrumento de la iniciativa popular en especial en la salud todavía es poco utilizado en Brasil y no se vislumbra un apoyo parlamentario para tales iniciativas.

Palabras-Ilave: Salud pública. Participación de la comunidad. Poder Legislativo.

\section{Introdução}

A Constituição Federal de 1988 (1) atribuiu aos cidadãos comuns a capacidade propositiva de leis por intermédio da participação política junto ao legislativo, instituindo os chamados mecanismos de exercício da soberania popular, compostos do sufrágio universal, o referendo, o plebiscito e a iniciativa popular (1). A iniciativa representou um marco político e jurídico no fortalecimento da democracia participativa.

O Brasil é o único país da América Latina a possuir a participação popular na formulação de leis federais. A iniciativa legislativa popular foi implantada pela primeira vez no processo constituinte de 1986-1988, que admitia emendas populares ao texto político. No entanto, esta modalidade não sobreviveu na redação final da Carta Política.

A Câmara dos Deputados e o Senado Federal compõem o Congresso Nacional, porém são regidos por normas distintas e têm funções bem delineadas na tarefa de legislar, mas ambas as casas legislativas têm mecanismos para a iniciativa popular.

A iniciativa popular constitucional, ou simplesmente iniciativa popular deve ter seu início na Câmara dos Deputados e seus requisitos estão dispostos no artigo 61, parágrafo $2_{-}^{\circ}$ da CF/88 (1), ou seja, a proposição legislativa ${ }^{2}$ deve estar acompanhada da assinatura de $1 \%$ do eleitorado nacional, distribuído ao menos em 5 estados com não menos que $0,3 \%$ dos eleitores, em cada um deles.

Certamente que esta modalidade de participação iniciativa popular na legislação, como descrito na CF/88 (1) não se dá de modo facilitado, dificultando ao cidadão a real participação na iniciativa do processo legislativo. É uma porta apenas semiaberta do parlamento que acaba por frustrar aqueles que desejam alterar ou criar pela lei alguma nova situação ou conjuntura.

Em face da configuração do instituto, poucos projetos de lei apresentados na Câmara dos Deputados, efetivamente se caracterizaram como de iniciativa popular. Geralmente,

\footnotetext{
2 Proposição Legislativa, segundo o Regimento Interno da Câmara dos Deputados (RICD), art. 100 é a "toda matéria sujeita à deliberação".
} 
esses projetos que recolheram assinaturas foram transformados em lei, mas tramitaram graças a co-autoria. ${ }^{3}$ Tais regramentos acabam por gerar uma democracia contemplativa (2) pelo afastamento da maioria da população das esferas de discussão e de tomada de decisões.

Há 15 anos, as casas legislativas estruturaram sistemas de comunicação envolvendo várias mídias atendendo à demanda social por informação e participação, favorecendo a participação social no processo legiferante. Na Câmara, em 2001, houve a criação da Comissão de Legislação Participativa (CLP), como parte da estrutura das comissões permanentes e com caráter técnico-legislativo composta por deputados federais (3). À CLP são submetidas as sugestões de iniciativa legislativa, de pareceres técnicos, de exposições e propostas oriundas de entidades científicas e culturais, associações, órgãos de classe, sindicatos e entidades organizadas da sociedade civil, exceto partidos políticos. Para os cidadãos individualmente apresentarem suas ideias legislativas, é possível utilizar o Banco de Ideias, também vinculado à Câmara. Tais ideias podem ser encampadas por algum deputado que oferecerá a respectiva proposição e dar início a tramitação legislativa.

No Senado Federal, por seu turno, foi criada em 2006, a Comissão de Direitos Humanos e Legislação Participativa (CDH) (4) que compete apreciar: a) sugestões legislativas apresentadas por associações e órgãos de classe, sindicatos e entidades organizadas da sociedade civil, exceto partidos políticos com representação política no Congresso Nacional e b) pareceres técnicos, exposições e propostas oriundas de entidades cientificas e culturais. Os cidadãos, individualmente, podem oferecer sugestões de alteração de leis vigentes ou mesmo sugestões de novas proposições legislativas no portal e-cidadania desde que sua ideia seja apoiada por no mínimo 20 mil eleitores (5).

Os jovens de até 19 anos das escolar públicas brasileiras podem, também, contribuir com sugestões legislativas. Trata-se do Projeto Jovem Senador que seleciona, por meio de um concurso de redação, 27 estudantes do ensino médio de escolas públicas estaduais para vivenciarem o trabalho dos senadores na capital federal. Como produto final deste encontro, os estudantes, com o auxílio dos Consultores Legislativos, têm sua ideia legislativa encaminhadas à CDH do Senado Federal, como Sugestões Legislativas (SUG) antes de tramitarem normalmente pelo Congresso Nacional.

\footnotetext{
${ }^{3}$ A co-autoria nesses casos ocorre quando um parlamentar acaba por assinar a autoria do PL de iniciativa popular, fazendo-o tramitar sob sua autoria.
} 
A intenção dessa formulação deliberacionista é a de, ao gerar espaços públicos de participação, reconhecer nos excluídos a qualidade de cidadãos.

As duas casas legislativas, por suas comissões, facilitaram o acesso das entidades da sociedade civil e do cidadão no sentido de apresentar sugestões de lei e outras proposições legislativas, em função da inexigibilidade do rito exaustivo de coleta de assinaturas de no mínimo três décimos por cento do eleitorado brasileiro. Deste modo, atualmente vige no Brasil vige cinco modalidades de participação social na formulação de leis: a) a iniciativa popular constitucional; b) a iniciativa legislativa proposta por pessoa jurídica à Câmara dos Deputados; c) a iniciativa legislativa proposta por pessoa jurídica ao Senado Federal; d) a iniciativa legislativa individual por meio de sugestão junto ao Portal eCidadania do Senado Federal ou Banco de Ideais, na Câmara dos Deputados; e) a iniciativa legislativa de estudantes das escolas públicas brasileiras por meio do Programa Jovem Senador.

A saúde, direito garantido constitucionalmente a todos e um dever do Estado cujos serviços e ações são de relevância pública é campo fértil para as proposições legislativas, especialmente de iniciativa parlamentar (6). No entanto, não são conhecidas de modo sistematizado as propostas de iniciativa popular em saúde, nas diferentes instâncias propositivas, na Câmara e no Senado Federal, onde tramitam sob a legenda de Sugestão Legislativa (SUG).

Deste modo é que se propôs a investigação nas bases de dados legislativos do Congresso Nacional a fim de responder à pergunta: quem propõe e o que propõe no âmbito da iniciativa popular legislativa e como o parlamento federal brasileiro tramita tais proposições de interesse da saúde.

\section{Metodologia}

Tratou-se de um estudo exploratório, descritivo e retrospectivo de base quantitativa, em base de dados secundários, disponíveis nos sítios das casas legislativas do Congresso Nacional.

Foram consultadas as bases de dados da Câmara dos Deputados e do Senado Federal, disponíveis em www.camara.gov.br e www.senadofederal.gov.br, respectivamente. $\mathrm{O}$ acesso a essas bases é público e desimpedido. 
A unidade de análise concentrou-se na proposição de Sugestão Legislativa de Iniciativa Popular e iniciativa legislativa, na área da saúde, no período entre janeiro de 2011 a dezembro de 2015, em que foi verificado a ementa, inteiro teor do texto propositivo e as exposições de motivos para a proposição.

Como critério de inclusão, foram contempladas todas as sugestões legislativas (SUG) que contivessem em sua ementa a palavra saúde e a leitura de seu inteiro teor revelasse compatibilidade com a temática. A exposição de motivos para a proposição foi utilizada para dirimir dúvidas sobre a proposta. Foram excluídas da pesquisa as SUG sobre outros temas que não guardaram alinhamento com o campo da saúde.

Os achados foram organizados em matrizes e planilhas eletrônicas, utilizando-se o software Excel versão 2013.

Foram analisadas as sugestões protocoladas no Sistema de Tramitação de Matérias, da Câmara dos Deputados - as convertidas em proposições legislativas e as arquivadas -, bem como seus respectivos pareceres. Também foram tabuladas as sugestões registradas na secretaria da CDH-Senado Federal e armazenadas nos arquivos da comissão e as propostas junto ao e-Cidadania.

\section{Resultados}

Uma das possibilidades de participação direta da população presente na Constituição Federal de 1988 é a iniciativa popular. Contudo, os requisitos legais para a apresentação de projetos de iniciativa popular são tão exigentes que dificultam a mobilização cidadã.

Igualmente, a tramitação de um projeto de lei de iniciativa popular é árdua e complexa garantindo uma consequente lentidão dos projetos de lei, os quais ao longo do fluxo acabam por perder seu objeto ou mesmo a falta de celeridade faz com que sejam arquivados ao final da legislatura. O fluxograma demonstra os inúmeros procedimentos que deve passar uma proposição para que possa converter-se em lei. 
Figura 1: Fluxograma da tramitação de um projeto de lei de iniciativa popular

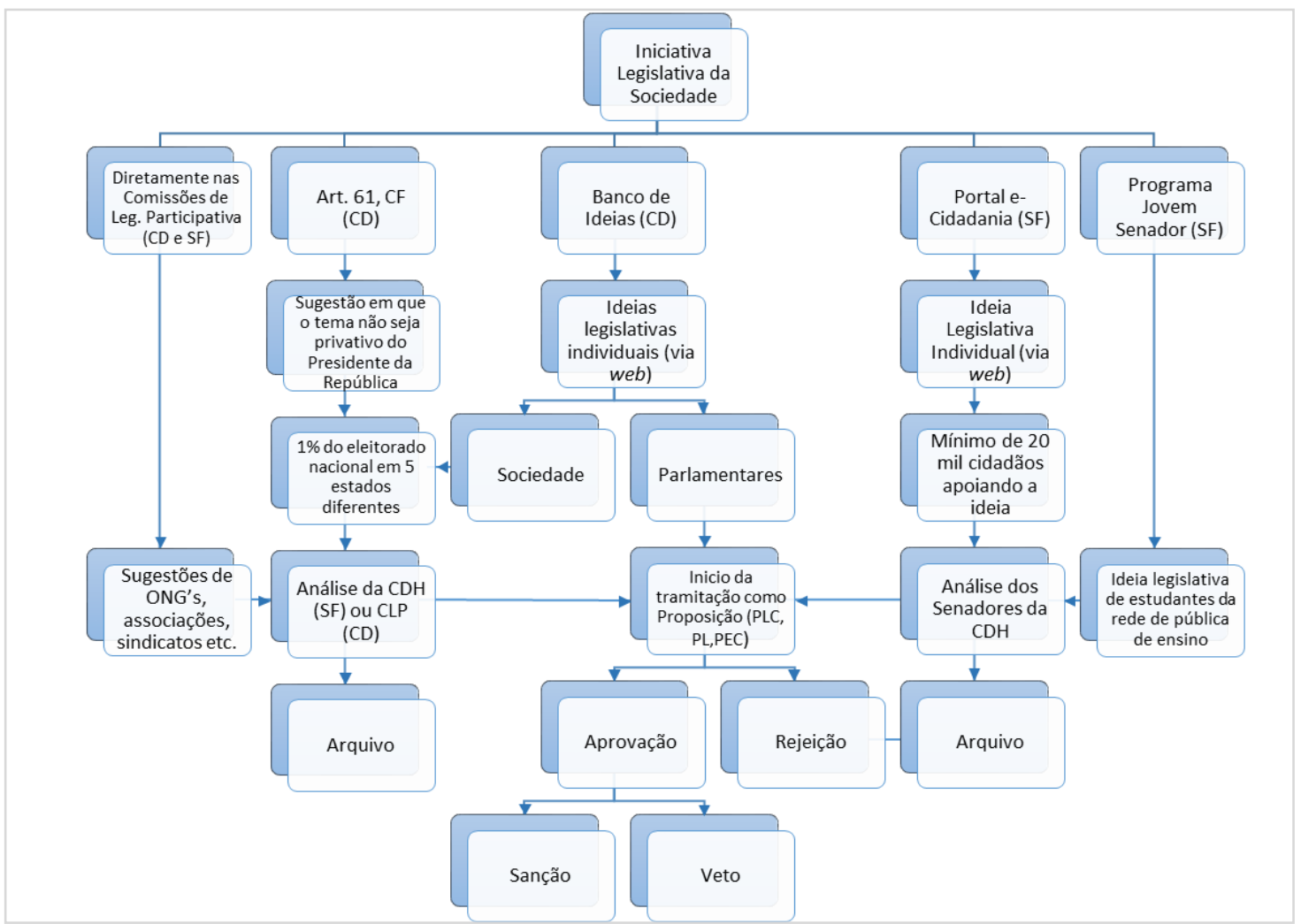

Fonte: Elaborado pelo autor com base no Regimento Interno da Câmara dos Deputados e Senado Federal e nos links http://www2.camara.leg.br/atividade-legislativa/comissoes/comissoespermanentes/clp/banideias.htm; https://www12.senado.leg.br/ecidadania/

Mas, apesar desse esforço hercúleo de avançar no processo legislativo, a pesquisa encontrou um total de 1838 projetos de lei sobre saúde, no período proposto, mas apenas 9 oriundos de sugestões legislativas de iniciativa popular (SUG). Desse total, 5 foram apresentadas na CDH do Senado Federal e 4 foram apresentadas na CLP da Câmara dos Deputados (Quadro 1). 
Cuadernos Iberomericanos

de Derecho Sanitario

Quadro 1- Sugestões Legislativas apresentadas no Congresso Nacional 2011-2015

\begin{tabular}{|c|c|c|c|c|c|}
\hline $\begin{array}{l}\text { Casa } \\
\text { Legislativa }\end{array}$ & $\begin{array}{l}\text { Proposição/ } \\
\text { n }^{\circ}\end{array}$ & Autoria & Ementa & Situação & $\begin{array}{l}\text { Transformad } \\
\text { o em lei }\end{array}$ \\
\hline \multirow{4}{*}{$\begin{array}{l}\text { Câmara } \\
\text { dos } \\
\text { Deputados }\end{array}$} & $\begin{array}{l}\text { CD-SUG } \\
3 / 2015\end{array}$ & $\begin{array}{l}\text { Instituto } \\
\text { Oncoguia }\end{array}$ & $\begin{array}{l}\text { Sugere a realização } \\
\text { do V Fórum Nacional } \\
\text { de Políticas de Saúde } \\
\text { em Oncologia }\end{array}$ & Arquivado & Não \\
\hline & $\begin{array}{l}\text { CD-SUG } \\
33 / 2015\end{array}$ & $\begin{array}{l}\text { Instituto } \\
\text { Oncoguia }\end{array}$ & 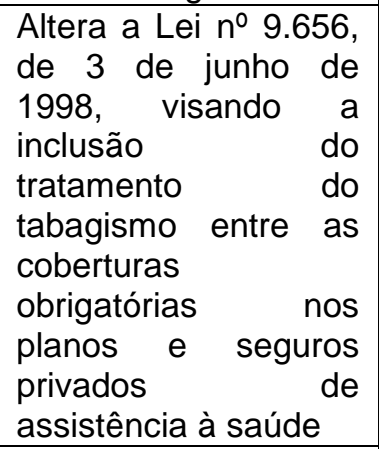 & $\begin{array}{l}\text { Transformada } \\
\text { no PL } \\
4478 / 2016\end{array}$ & Não \\
\hline & $\begin{array}{l}\text { CD-SUG } \\
14 / 2014\end{array}$ & $\begin{array}{l}\text { Centro } \\
\text { Desenvolvimen } \\
\text { to Social } \\
\text { Convida }\end{array}$ & \begin{tabular}{lr}
\multicolumn{2}{l}{ Sugere projeto de lei } \\
que regulamenta a \\
profissão & de \\
Conselheiro & em \\
Dependência & \\
Química. & \\
\end{tabular} & $\begin{array}{l}\text { Transformado } \\
\text { no PL } \\
2908 / 2015\end{array}$ & Não \\
\hline & $\begin{array}{l}\text { CD-SUG } \\
89 / 2013\end{array}$ & $\begin{array}{l}\text { Conselho } \\
\text { Nacional de } \\
\text { Saúde }\end{array}$ & $\begin{array}{l}\text { Altera dispositivos da } \\
\text { Lei Complementar } n^{\circ} \\
141 \text {, de } 13 \text { de janeiro } \\
\text { de } 2012\end{array}$ & $\begin{array}{l}\text { Transformado } \\
\text { no PLP } \\
321 / 2013\end{array}$ & Não \\
\hline \multirow{5}{*}{$\begin{array}{l}\text { Senado } \\
\text { Federal }\end{array}$} & $\begin{array}{l}\text { SF-SUG } \\
8 / 2014\end{array}$ & $\begin{array}{l}\text { Portal e- } \\
\text { Cidadania }\end{array}$ & $\begin{array}{llr}\text { Regular o uso } & \text { uso } \\
\text { recreativo, medicinal } \\
\text { e industrial da } \\
\text { maconha }\end{array}$ & $\begin{array}{l}\text { Aprovado na } \\
\mathrm{CDH}\end{array}$ & Não \\
\hline & $\begin{array}{l}\text { SF-SUG } \\
18 / 2014\end{array}$ & $\begin{array}{l}\text { Projeto } \\
\text { Senador Jovem }\end{array}$ & $\begin{array}{l}\text { Proíbe a utilização de } \\
\text { royalties de petróleo } \\
\text { para outros fins que } \\
\text { não o financiamento } \\
\text { da saúde e educação }\end{array}$ & $\begin{array}{l}\text { Em tramitação } \\
\text { na CDH }\end{array}$ & Não \\
\hline & $\begin{array}{c}\text { SF-SUG } \\
7 / 2013\end{array}$ & $\begin{array}{l}\text { Associação } \\
\text { Brasileira de } \\
\text { Autoprograma } \\
\text { de Saúde- } \\
\text { ABRAPS } \\
\end{array}$ & $\begin{array}{lr}\text { Dispõe } & \text { sobre } \\
\text { autoprograma } & \text { de } \\
\text { saúde, ou } & \text { cartão } \\
\text { saúde e dá } & \text { outras } \\
\text { providências } & \\
\end{array}$ & $\begin{array}{l}\text { Transformado } \\
\text { no PLS } \\
467 / 2013\end{array}$ & Não \\
\hline & $\begin{array}{c}\text { SF-SUG } \\
3 / 2011\end{array}$ & $\begin{array}{l}\text { Universidade } \\
\text { FEEVALE }\end{array}$ & $\begin{array}{l}\text { Regulamenta } \\
\text { exercício da profissão } \\
\text { de Quiropraxista }\end{array}$ & $\begin{array}{l}\text { Transformado } \\
\text { no PLS } \\
599 / 2011\end{array}$ & Não \\
\hline & $\begin{array}{l}\text { SF-SUG } \\
20 / 2011\end{array}$ & $\begin{array}{l}\text { Projeto } \\
\text { Senador Jovem }\end{array}$ & $\begin{array}{l}\text { Altera a Lei } 8080 / 90 \\
\text { para obrigar a } \\
\text { contratação pelo SUS } \\
\text { de profissionais de } \\
\text { saúde recém- } \\
\text { formados da rede } \\
\text { pública de ensino }\end{array}$ & $\begin{array}{l}\text { Transformado } \\
\text { no PLS } \\
352 / 2015\end{array}$ & Não \\
\hline
\end{tabular}

Fonte: Web Site do Senado Federal e da Câmara dos Deputados (www.camara.gov.br e www.senadofederal.gov.br) 
Os projetos de lei de iniciativa popular que tramitam no Congresso versam e apresentam ações em diversos seguimentos da saúde como: financiamento do SUS, álcool e drogas, saúde suplementar, saúde do trabalhador, saúde mental, saúde escolar, terapias, profissionais e regulamentação de novas profissões de saúde.

No Banco de Ideais da Câmara foram encontradas 35 manifestações de cidadãos individualmente na categoria Direitos Sociais, tópico saúde. Dentre estas proposições, nenhuma ideia foi acolhida por parlamentares ou pela sociedade para iniciar o tramite formal como projeto de lei. (Gráfico 1)

Gráfico 1- Temas das Sugestões Legislativas no Banco de Ideias da Câmara dos Deputados 2011-2015

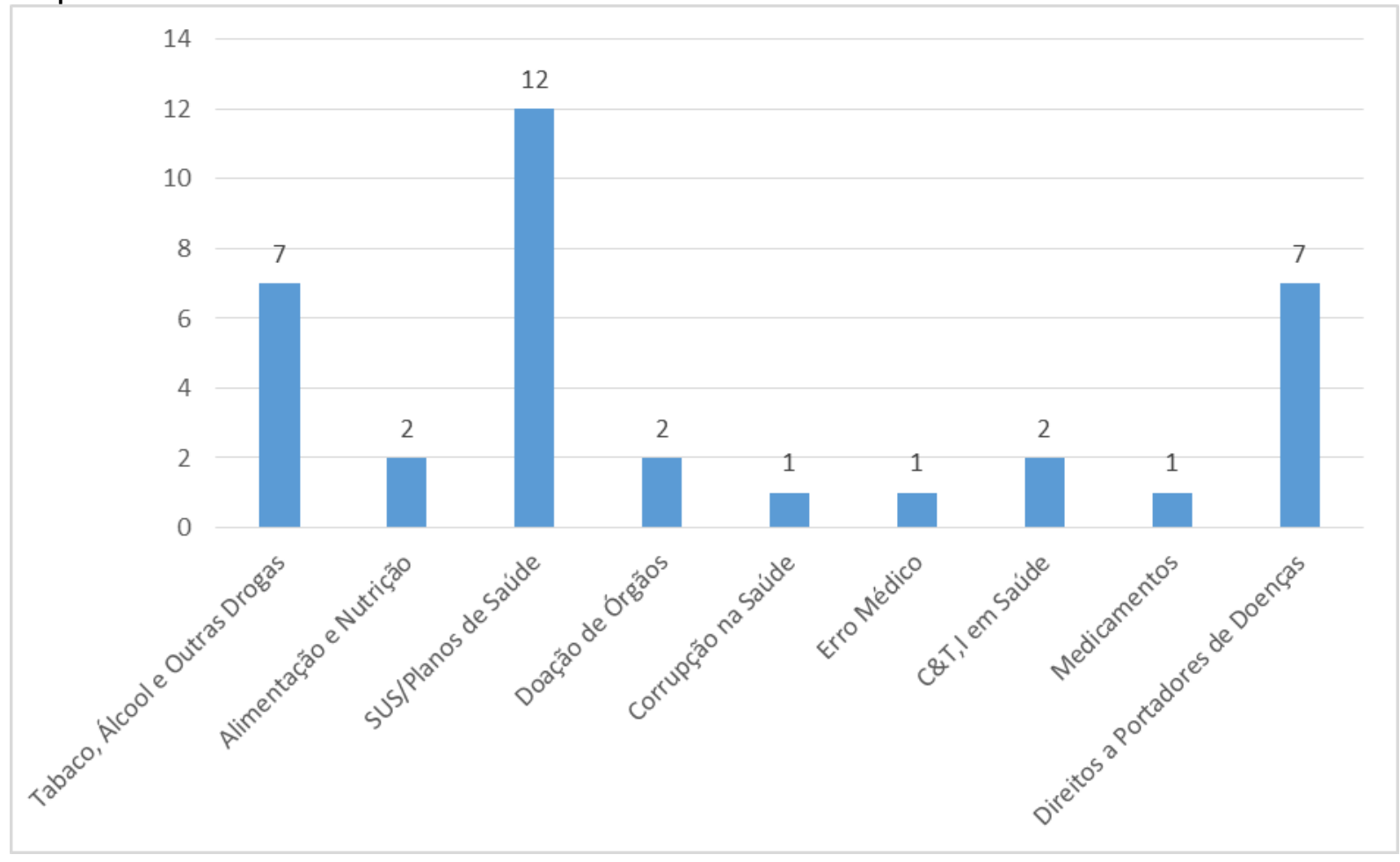

Fonte: Banco de Ideias da Câmara dos Deputados

No Portal e-Cidadania, foram encontradas 71 sugestões legislativas sobre saúde a qual apenas a proposição que busca regular o uso recreativo/ medicinal da maconha foi discutida na CDH devido a mobilização social frente a esta questão. 
Gráfico 2- Temas das Sugestões Legislativas portal e-cidadania do Senado Federal 20112015

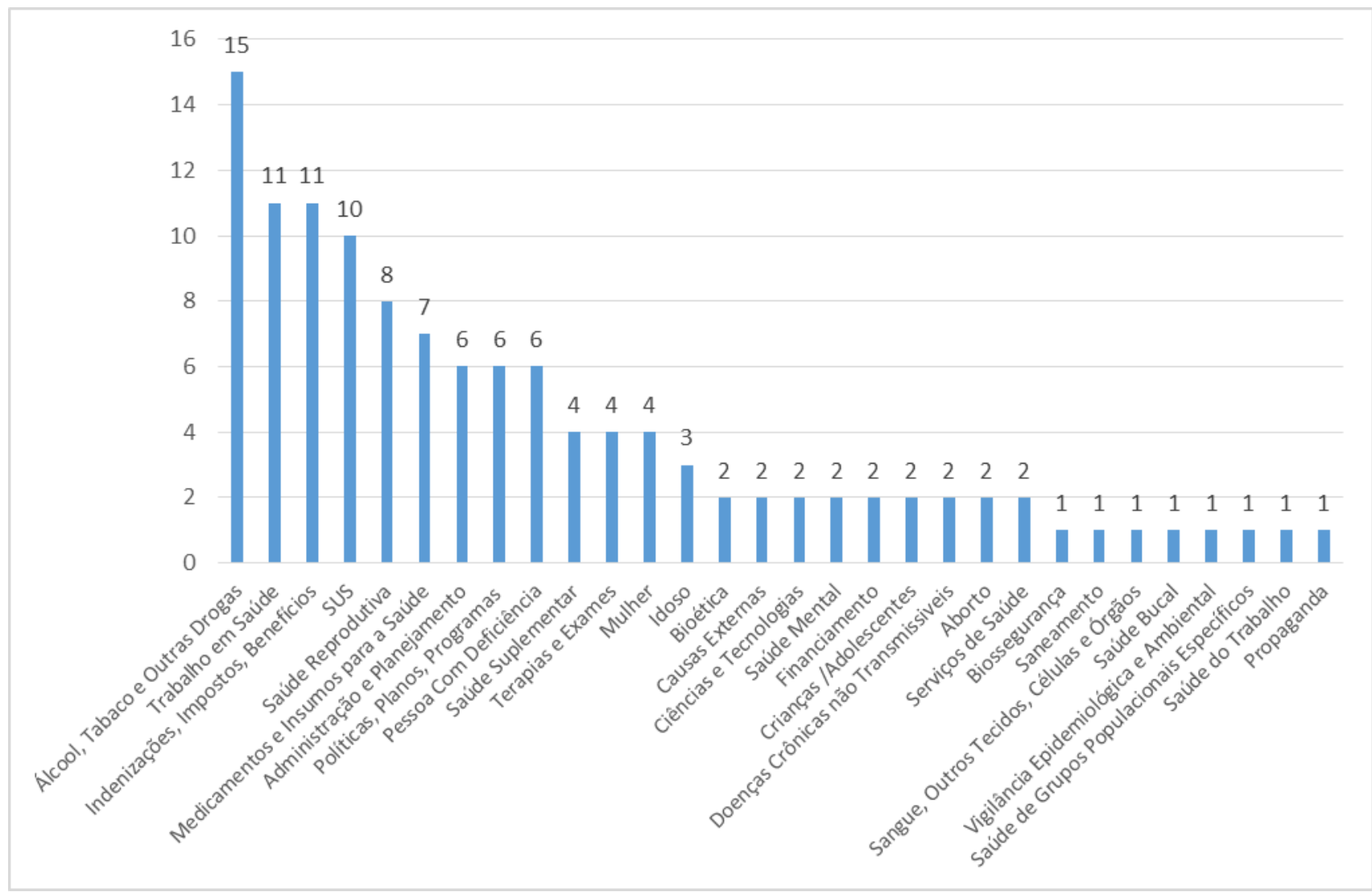

Fonte: Portal e-cidadania

Observou-se que $50 \%$ das sugestões legislativas iniciaram sua tramitação com solicitações diretamente nas Comissões de Legislação Participativa do Senado Federal e da Câmara dos Deputados enquanto segunda porta de entrada mais frequente para a apresentação de propostas de projetos de lei deu-se por meio do Projeto Jovem Senador em $30 \%$ das sugestões legislativas.

De todos os projetos, o Saúde Mais Dez (SUG 89/2013) foi o único projeto de lei de iniciativa popular fundamentado no artigo $61 \S^{\circ}$ da Constituição Federal com cerca de 1,9 milhão de eleitores apoiando tal inciativa.

Das 9 (nove) sugestões, 7 (sete) foram analisadas pelas respectivas comissões na mesma sessão legislativa resultando em 1 arquivamento (CD-SUG 3/2015) e 5 (cinco) iniciaram a sua tramitação conformando-se em projeto de lei (SUG-SF 7/2013, SUG-SF 3/2011, SUG-CD 33/2015, SUG-CD 89/2013 e SUG-CD 14/2014). 
A proposição (SUG-SF 20/2011) foi transformada em Projeto de Lei ao final de 4 (quatro) anos, e duas últimas proposições ainda estão em tramitação (SUG-SF 8/2014 e SUG-SF 18/2014).

\section{Discussão}

A CLP não é atrativa para os parlamentares, é a comissão que tem menos proposições apreciadas, menor número de reuniões e menor média de presença parlamentar nas suas reuniões (6).

Os próprios parlamentares parecem não se interessar pelo órgão, pois é fato que em fins de abril de 2007 (dois meses após início dos trabalhos legislativos), 13 das 36 vagas de membros suplentes e titulares existentes, ainda não haviam sido ocupadas (7). Ademais, nos estudos de Ferreira (7) fica demonstrado que apesar dos anos de atuação da Comissão de Participação Popular na Câmara, a baixa efetividade fica evidente pois apenas uma única proposição logrou vencer as barreiras do processo legislativo e transformar-se em lei.

Essas questões internas refletem como a instituição encara a participação popular. A relação entre representantes e representados é um contrato em que cada uma das partes exerce um papel estanque - uma relação bem diferente, portanto, da que vem sendo identificada por Bernard Manin (8) e pelos demais estudiosos das metamorfoses da representação no contexto do que o primeiro convencionou chamar de "democracia de auditório".

O estudo demonstrou que as proposições na área da saúde têm iniciativa de entidades vinculadas a determinadas doenças e que os projetos de lei de iniciativa individual do cidadão não foram encontrados na pesquisa. Este último, que tem o portal ecidadania e o Banco de ideias como principal ferramenta, apresentam propostas de lei com baixa qualidade argumentativa e estrutural para convencer a sociedade ou os deputados de que tais propostas seriam necessárias ao desenvolvimento do país, isto explica, em grande parte, baixo interesse dos atores nestes recursos de participação.

Até a data de redação deste artigo nenhuma das proposições de saúde apresentadas seja na Câmara dos Deputados, seja no Senado Federal transformaram-se em lei, confirmando-se o resultado encontrado por Ferreira (7). 


\section{Conclusão}

É inegável que é melhor ter-se meios para que a participação popular de leis possa ocorrer no Brasil que nenhum mecanismo, como outrora.

Mas não se duvida que as atuais formas de participação merecem ser incrementadas pelas casas legislativas componentes do Congresso Nacional para que a diretriz constitucional seja plenamente realizada pelo cidadão comum.

Em matéria de saúde, a participação popular na iniciativa de leis para o setor é inexpressiva, faltando ao cidadão comum orientação e estímulo para que promova esse seu direito garantido em sede constitucional. Deste modo, para além das iniciativas de entidades públicas e privadas encontradas na pesquisa, é necessário um esforço do poder legiferante do Estado no sentido de estimular e agregar propostas dos cidadãos, visto ser ele o destinatário final da norma jurídica.

\section{Referências}

1- Brasil. Constituição da República Federativa do Brasil de 1988. Brasília: Senado Federal, 2015.

2 Benevides, MVM. Cidadania e Democracia. Revista Lua Nova, 33(94): 5-16

3 - Brasil. Regimento Interno da Câmara dos Deputados - RICD. Câmara dos Deputados, Congresso Nacional. Disponível em http://www2.camara.leg.br/atividadelegislativa/legislacao/Constituicoes Brasileiras/regimento-interno-da-camara-dosdeputados [Acesso em 29.4.2016]

4 Brasil. Regimento Interno do Senado Federal - RISF. Senado Federal, Congresso Nacional. Disponível em http://www25.senado.leg.br/web/atividade/regimento-interno [Acesso em 29 abr 2016]

5 Brasil. Portal e-cidadania. Senado Federal, Congresso Nacional. Disponível em http://www12.senado.leg.br/ecidadania/principalideia [Acesso em 29 abr 2016]

6 LIN, NSY. Participação popular no legislativo federal. Tese defendida junto ao Departamento de Ciência Política da Faculdade de Filosofia, Letras e Ciências Humanas da USP. São Paulo, 2010.

7 Ferreira Jr. NA. Comissão de Legislação Participativa: a construção da democracia deliberacionista. Brasília: E-legis 1: 36-43, 2008.

8 Manin, B. As metamorfoses do governo representativo. Revista Brasileira de Ciências Sociais. n. 29. 2000. Disponível em 
Cadernos Ibero-Americanos

de Direito Sanitário

Cuadernos Iberomericanos

de Derecho Sanitario

http://www.anpocs.org.br/portal/publicacoes/rbcs_00_29/rbcs29_01.htm. [Acesso em 8.jan.2017] 